\title{
Enunciación
}

http://revistas.udistrital.edu.co/ojs/index.php/enunc

DOI: http://dx.doi.org/10.14483/udistrital.jour.enunc.2016.2.a05

enunciación

Artículo de REFLEXIÓN

\section{Búsqueda inductiva de datos y proyectos de investigación en lengua materna}

\author{
Inductive search of data and research projects in a mother language
}

\author{
Éder García-Dussán ${ }^{1}$
}

Para citar este artículo: García-Dussán, E. (2016). Búsqueda inductiva de datos y proyectos de investigación en lengua materna. Enunciación, 21(2) 238-255.

Recibido: 25-abril-2016 / Aprobado: 28-octubre-2016

\section{Resumen}

En este artículo se aborda el problema de cómo iniciar un proceso investigativo en el campo de la comunicación escolar en lengua materna y, con el fin de orientar un camino que permita avanzar en este sentido, se exponen las fases que requiere un docente-investigador para la construcción de un proyecto de investigación como condición previa para la expresión sistemática de un problema de investigación que toma como objeto de estudio procesos lingüísticos como la lectura, la escritura, el habla, la escucha o las experiencias estéticas. Para dar cuenta de esto, nos basamos en los principios metodológicos de Tamayo y Tamayo (2004), los cuales se ejemplifican con un hipotético caso que revela los detalles que preceden a la escritura de un proyecto $y$, por tanto, a la consolidación de los elementos constitutivos de la sintaxis de un problema investigativo. El resultado de este esfuerzo deja ver la utilidad del razonamiento inductivo a propósito de la intención de obtener saber pedagógico a través de la indagación desde el aula y para los actores de la escuela.

Palabras clave: trabajo de campo, inducción, proyecto de investigación.

\begin{abstract}
The article discusses the problem of how to start a research process in the field of school communication in a mother language and, in order to guide a path that will allow progress in this regard, it exposes the phases that requires a teacher-researcher for the construction of a research project as a precondition for systematic expression of a research problem which takes as its object of study linguistic processes such as reading, writing, speaking, listening or aesthetic experiences. To achieve this, we take into account the principles of the proposal of Tamayo and Tamayo (2004), which are exemplified by a hypothetical case that reveals the details that precede the writing of a project and, therefore, to the consolidation of the constitutive items of the syntaxes of a research problem. The result of this effort shows the usefulness of inductive reasoning concerning the intention to obtain pedagogical knowledge through inquiry from the classroom to the school performers.
\end{abstract}

Keywords: fieldwork, induction, research project.

1 Docente de tiempo completo, Universidad Distrital “Francisco José de Caldas", Bogotá (Colombia). Correo electrónico: eagarciad@udistrital.edu.co 


\section{INTRODUCCIÓN}

Si tomamos en serio aquella intuición que confirma que, en sus entrañas, todo discurso contiene estructuras metafóricas tomadas de la vida cotidiana (Lakoff y Johnson, 2004), es posible comparar la acción de investigar con la de jugar ping-pong (Parra, Parra y Lozano, 2006), puesto que en ese juego la acción del jugador está oscilando en dos campos y disfruta de una mediación. En efecto, el 'juego investigativo' se inicia cuando el docente-investigador decide comenzar su acción desde un campo (realidad escolar [RE] o teoría [T]) (figura 1) y, si el jugador desea tener éxito en su investigación, debe hacer que la pelota llegue, usando sus propios medios, al orbe adjunto.

Esta analogía permite, entonces, entender los caminos de razonamiento que se pueden seguir a la hora de iniciar un proceso investigativo; a saber: el inductivo o el deductivo. Si alguien decide jugar con la lógica del primero, como es el caso de la tradición en la Maestría en Pedagogía de la Lengua Materna (MPLM), de la Universidad Distrital Francisco José de Caldas, este investigador debe tomar una raqueta, una pelota y jugar del lado de la realidad escolar (RE) hasta que, usando sus propias fuerzas, tarde o temprano, esa bola descienda en el orbe de la teoría (T). Dicho de otra forma, quien aprecia el camino inductivo, funda una investigación desde el aula y no del aula o sobre el aula (Baquero, 2006); eso sí, sin desdeñar la existencia de otros caminos de construcción de proyectos investigativos.

Así, pues, este es el camino de indagación que, en lo que sigue, esbozará las estratagemas cuando se trata de adelantar una investigación en el vasto e interdisciplinar campo de pedagogía en lengua materna en la MPLM con el fin de detallar, a través de una simulación, los pasos a seguir. Para mostrar este camino (methodus -meta-hodos- significa "camino a seguir"), dividiremos en tres pasos o fases la propedéutica que lleva a la construcción de un proyecto de investigación (acción) en el campo de la pedagogía de la lengua materna, y luego concluiremos en

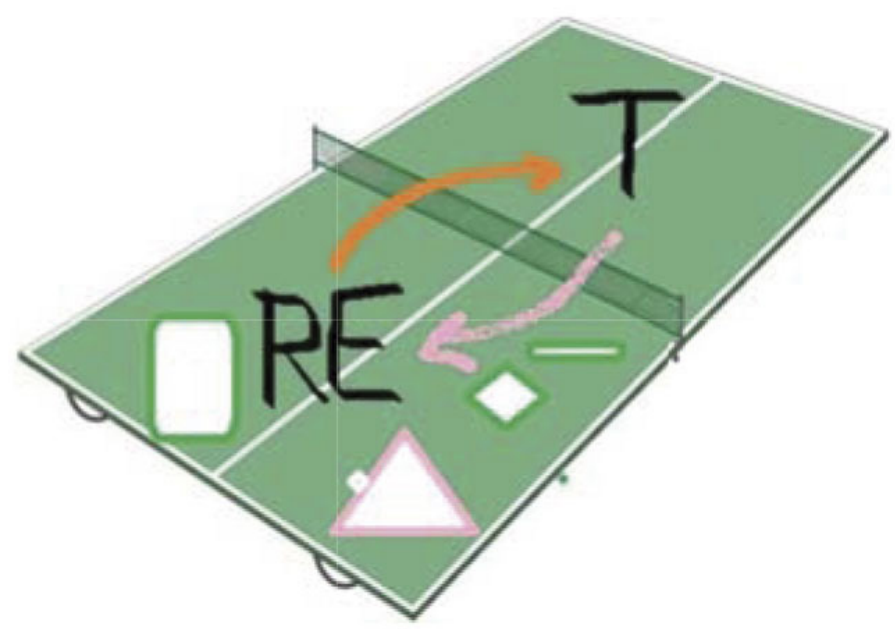

Figura 1. Posibilidades de investigar en el área de lengua materna Fuente: elaboración propia. 
un sentido teórico a propósito de las ventajas de la investigación inductiva en las ciencias del lenguaje.

\section{LA ELECCIÓN DE UN ÁREA TEMÁTICA Y TRABAJO DE CAMPO}

Para iniciar un proceso de investigación tal como proponemos, nos guiaremos de las claves metódicas y epistémicas sugeridas por el investigador colombiano Mario Tamayo y Tamayo (2011, p. 116), quien propone un esquema general de la investigación cualitativa cuya vía es inductiva; para lograr esto, se debe comenzar con la elección de un tema el cual, una vez planteado y delimitado, permita destilar un problema, el cual se acompaña de objetivos y se enmarca teórica y metodológicamente.

En el caso de la investigación en pedagogía de la lengua materna, Los lineamientos curriculares de lengua castellana (MEN, 1998) ofrecen una inicial y excelente guía para localizar el tránsito tema-problema a través de la determinación de cinco ejes en los cuales puede anclarse el docente-investigador interesado en generar saber pedagógico en el área interdisciplinar de la lengua materna. Así, pues, aparece el eje de los procesos de producción e interpretación de textos, que dialoga muy bien con el de los principios de interacción y procesos culturales implicados en la ética comunicativa; mientras que el eje de los procesos de producción de sistemas de significación se fusiona solidariamente con el de los procesos de desarrollo del pensamiento. Finalmente, está el tercer eje, referido a los procesos culturales y estéticos, asociados al lenguaje y el papel discreto de la literatura en este y que funge como bisagra de los otros ejes temáticos. Esto se observa de una forma más detallada en la tabla 1 .

Llevado esto a la realidad y tradición de la Maestría en Pedagogía de la Lengua Materna, de la Universidad Distrital (MPLM, UD), estos cinco ejes admiten proyectarse en tres grandes modalidades, las cuales actúan como conexos temáticos de investigación en lenguas-idioma, tal como se muestra en la figura 2.

Esta organización de tópicos es útil a la hora de rastrear posibilidades, y sobre ella se pueden proyectar ciertos órdenes para constatar un tema de investigación cuya elección se apoya diagnosticando preceptos subjetivos, como: el interés por el área temática, la capacidad cognoscitiva y las experiencias previas en esta por parte del investigador; pero también, y al tiempo, preceptos de orden objetivo, como: la proyección de un diseño investigativo; la utilidad e impacto a nivel local, regional o nacional; la atención a los beneficiarios inmediatos, y la generación de saber pedagógico previsto (Tamayo y Tamayo, 2011, p. 121).

Una vez valorada la elección del área temática y su viabilidad investigativa, apertura determinante de su acción inductiva, el docente-investigador inicia una inmersión en el campo de la realidad escolar, lo cual implica ejecutar un trabajo que, tomando como base el recorrido de estos ejes, le permita ver, no solo los problemas que atañen al área de lengua castellana, sino también le obliga a cuestionarse sobre la figura docente lo cual dispara, al menos, dos determinaciones, a saber:

(i) La mirada a la experiencia concreta y a las acciones propias del docente y de sus pupilos.

(ii) La justificación de un proceso de investigación cuya meta no es la teoría, sino el desarrollo de supuestos para actuar en el aula de otra forma y, desde allí, generar un saber pedagógico.

Ahora bien, esta actitud consiente un tránsito importante, el del docente-funcionario a sujeto-explorador y observador; pivote que, a la postre, le permite encumbrarse como un etnógrafo del aula. Finalmente, la suma de estos 
roles lo constituirán como docente-investigador, diferenciado de los demás colegas por cualificar acciones cognitivas que comienzan con la de husmear el entorno cosificado. Esto hace que se avance bajo los siguientes pasos progresivos:

- Observar y describir acciones del aula. Esta doble acción permite re-significar a todos los actores de la escuela como si pertenecieran a universos foráneos, incluyendo al observador mismo; por lo cual se suspende y se pone entre paréntesis la realidad cotidiana del aula.

- Recoger información y organizarla. El observador, ahora foráneo de su propia cotidianidad, ahora centra su labor en fijar lo visto; esto es, en captar y tipificar. Y para lograr esto, ya en su rol de etnógrafo, busca ejercicios orales de interlocución a través de encuestas y entrevistas, redacta diarios de campo, acopia talleres diagnósticos, lee documentos teóricos e institucionales, acumula datos representativos y empíricos del área temática que rastrea, etc.

- Describir y analizar los datos. Luego llega el momento de mayor creatividad y mesura de la labor etnográfica. Aquí el docente se vislumbra ya como investigador en ciernes, y se enfrenta al material recogido, mero insumo para la producción de una pregunta directriz.

En este último punto, los investigadores en educación Parra, Parra y Lozano (2006) expertos en nuestro ámbito local en proponer esbozos de investigación etnográfica, usan otra imagen, y es la de un sujeto que consume una alcachofa. Es que, en la descripción y el análisis de datos, se trata de penetrar desde la superficie hacia el fondo la realidad escolar (RE) que se presenta como una unidad compleja y entrelazada; esto es, consiste en re-escribirla densamente (Geertz, 1998), para luego des-anudarla o de des-doblarla ${ }^{2}$. Esto

2 Efectivamente, desde una revisión etimológica, describir significa "escribir de arriba hacia abajo" (mientras que inscribir es lo contrario). Asimismo, explicar es "sacar pliegues" o "desplegar"; y analizar es la acción de soltar o desanudar completamente lo que está arriba, en la superficie. hace que, en este momento de la práctica investigativa, describir-analizar-explicar se conviertan en acciones cognitivas progresivas que tienen la meta de sacar a flote unas categorías que se puedan relacionar bajo la relación de co-dependencia. Así, pues, si seguimos explotando la imagen alimentaria propuesta por Parra, Parra y Lozano, quien desea consumir el vegetal nombrado comienza a comerlo removiendo las hojas externas hacia su corazón y,

[...] entre más se acerca uno al centro de la alcachofa más carne se encuentra en las hojas. Hasta que la desnuda completamente y se encuentra con el corazón de la alcachofa, o sea, el fenómeno, o si se quiere, el concepto que se busca. Hay que tener en cuenta, sin embargo, que no solo es importante el corazón de la alcachofa sino también las hojas externas. Estas hojas pueden pensarse como la apariencia que esconde lo que buscamos. Pero la apariencia suele ser parte sustancial de lo escondido. La cotidianidad del mundo escolar esconde a nuestros ojos los fenómenos que buscamos (Parra, Parra y Lozano, 2006, pp. 91-92).

Es así como se dice con frecuencia que un buen investigador es quien, con la experiencia misma de investigar, perfecciona su mirada ('tiene ojo clínico') y afina su actitud de expedicionario ('escrudiña como cazador'); cualidades que le permiten describir la realidad, analizarla y arriesgarse a pensar su trans-formación. Y, tal como en el arte de la montería, deber aprender a ojear, hojear, observar, predecir y, finalmente, limitar su zona de búsqueda, con la certeza de que logrará su meta (Velasco, 1999).

\section{ELTRÁNSITO DELTEMAAL PROBLEMA}

Ahora bien, el observador ejecuta la locomoción del tema -o área temática de investigación- hacia la producción de un problema investigable cuando, en el resultado de una observación, descubre una ausencia o dificultad 
Tabla 1. Ejes de los lineamientos curriculares de la lengua castellana (1996)

\begin{tabular}{|c|c|c|}
\hline Eje & Definición & $\begin{array}{c}\text { Temáticas que se pueden volver } \\
\text { problemáticas de investigación desde } \\
\text { el aula de clase }\end{array}$ \\
\hline $\begin{array}{l}\text { Procesos de construcción de sistemas } \\
\text { de significación y por medio de los } \\
\text { cuales se da la comunicación }\end{array}$ & $\begin{array}{l}\text { Conjunto de signos, símbolos, reglas } \\
\text { sintácticas, pragmáticas, contextos } \\
\text { de uso. Por ejemplo: lenguaje verbal } \\
\text { (oralidad, escritura...), lenguajes de } \\
\text { la imagen (cine, publicidad, caricatu- } \\
\text { ra...)... }\end{array}$ & $\begin{array}{l}\text { - Construcción: Acercamiento de los niños a la } \\
\text { lengua escrita en los primeros años de escolari- } \\
\text { dad. } \\
\text { - Uso: Prácticas de lectura, escritura, oralidad, el } \\
\text { lenguaje de la imagen. } \\
\text { - Explicación: La lengua como objeto de estudio, } \\
\text { la imagen y su funcionamiento, el cine y sus } \\
\text { reglas de funcionamiento, etc. } \\
\text { - Control: la regulación consciente de los siste- } \\
\text { mas de significación con finalidades comunica- } \\
\text { tivas. }\end{array}$ \\
\hline $\begin{array}{l}\text { Procesos de interpretación y } \\
\text { producción de textos }\end{array}$ & $\begin{array}{l}\text { Condiciones de comprender y } \\
\text { producir tipos de textos según sus } \\
\text { necesidades de comunicación. }\end{array}$ & $\begin{array}{l}\text { - Tipología textual en modalidad oral o escrita. } \\
\text { - Procesos de comprensión y producción: nive- } \\
\text { les intratextual, intertextual, extratextual. } \\
\text { - Coherencias lineal, semántica y pragmática. } \\
\text { - Proceso lector. }\end{array}$ \\
\hline $\begin{array}{l}\text { Procesos culturales y estéticos } \\
\text { asociados al lenguaje: el papel de la } \\
\text { literatura }\end{array}$ & $\begin{array}{l}\text { Entendida como una experiencia } \\
\text { de lectura que se ejecuta desde la } \\
\text { sensibilidad, la imaginación y claves } \\
\text { sensoriales. }\end{array}$ & $\begin{array}{l}\text { - Paradigmas desde los cuales profundizar en la } \\
\text { enseñanza de la literatura. } \\
\text { - Intertextualidad en contextos intersemiológi- } \\
\text { cos. } \\
\text { - Competencia literaria. } \\
\text { - Concepciones docentes sobre la didáctica } \\
\text { literaria: Literatura y competencia lingüística, } \\
\text { literatura y enseñanza de valores, literatura y } \\
\text { afianzamiento de la oralidad, la lectura y la } \\
\text { escritura, literatura y análisis interdisciplinar de } \\
\text { ciertas obras literarias. }\end{array}$ \\
\hline $\begin{array}{l}\text { Procesos culturales implicados en la } \\
\text { ética de la comunicación }\end{array}$ & $\begin{array}{l}\text { Trabajo sobre los derechos y deberes } \\
\text { de la comunicación, y sobre sus } \\
\text { límites y alcances. }\end{array}$ & $\begin{array}{l}\text { - El desarrollo de la oralidad y creación de lazos } \\
\text { sociales (turnos, cortesías, formalidad, cultura de } \\
\text { la argumentación en el aula, etc.). } \\
\text { - La diversidad cultural a nivel de sistemas de } \\
\text { valores, lógicas y formas de comprender e inter- } \\
\text { pretar el mundo. } \\
\text { - Diversidad cultural y el español como lengua } \\
\text { extranjera (etnoeducación). }\end{array}$ \\
\hline $\begin{array}{l}\text { Procesos de desarrollo del pensa- } \\
\text { miento }\end{array}$ & $\begin{array}{l}\text { Estructuras de pensamiento y de } \\
\text { acción que los niños adquieren en } \\
\text { el enfrentamiento con la realidad } \\
\text { social. }\end{array}$ & $\begin{array}{l}\text { - Relaciones pensamiento-lenguaje-realidad. } \\
\text { - Competencias cognitivas: toma de apuntes, } \\
\text { estilos de enseñanza estilos de aprendizaje, etc. } \\
\text { - Lectura y escritura como procesos cogniti- } \\
\text { vos: las inferencias, la pregunta antes de leer, } \\
\text { la evaluación de alcances después de leer, la } \\
\text { construcción de macroestructuras, la edición, el } \\
\text { parafraseo, la relectura, etc. } \\
\text {-Cultura del pensamiento o conciencia de } \\
\text { procesos como describir, comparar, contrastar, } \\
\text { analizar, sintetizar, clasificar, jerarquizar, argu- } \\
\text { mentar... }\end{array}$ \\
\hline
\end{tabular}

Fuente: elaboración propia. 


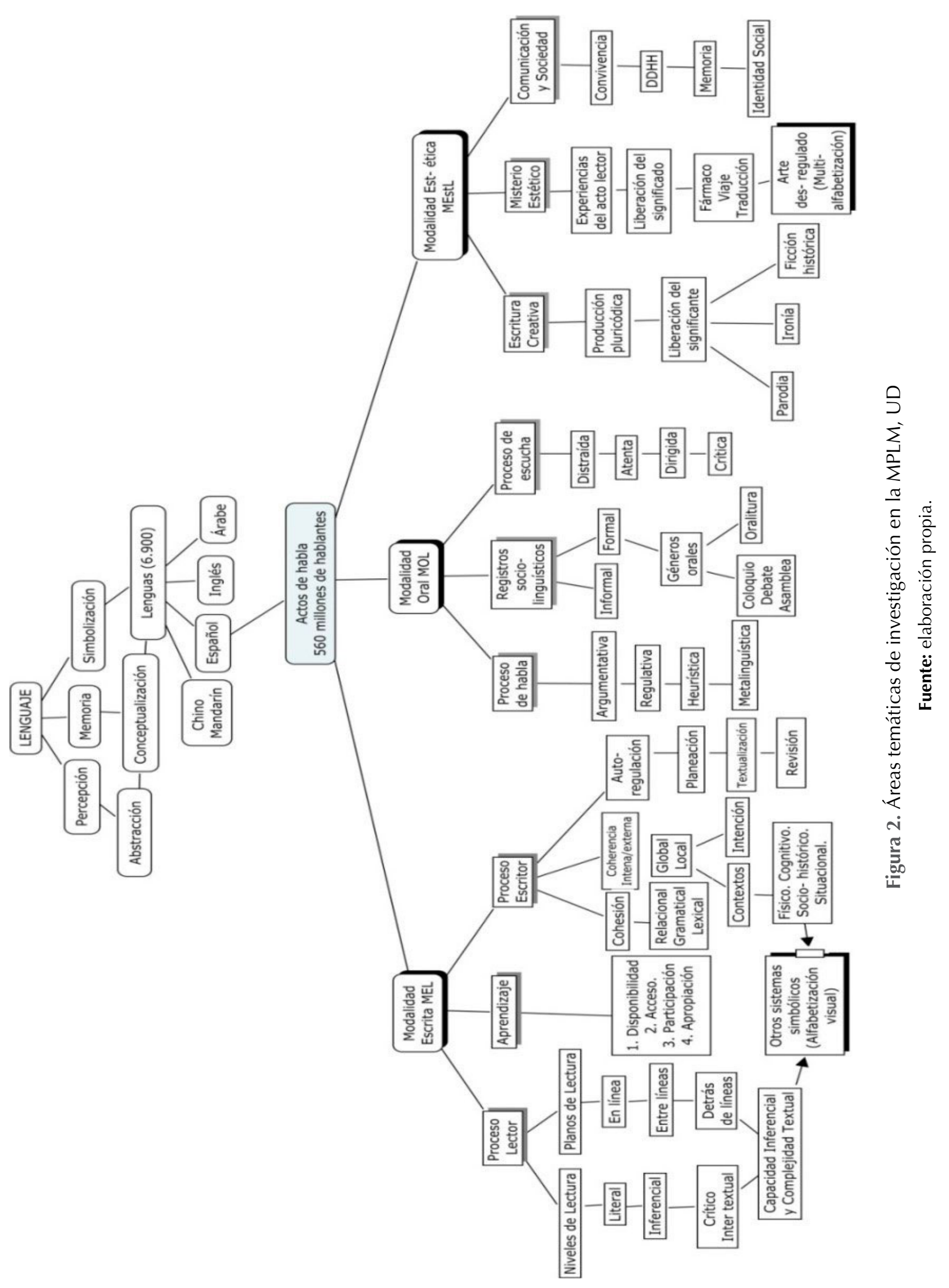


observable. Esta búsqueda se logra a través de preguntas iniciales que pueden seguir el siguiente esquema asociativo a partir de los adverbios de interrogación dónde (espacio), cuándo (tiempo), cómo (modo, manera), a quién/cuál (interlocutor, receptor, beneficiario...), qué (objeto), para qué (finalidad) y por qué (causa). Así, por ejemplo, para reducir la generalidad e incertidumbre a la que se enfrenta el docente-investigador es útil preguntarse ¿para qué del dónde y el cómo?; ¿por qué del cómo, del cuándo, del dónde y del quién?; o ¿qué del cuándo y del quién?, entre otras posibilidades. Acción que, por cierto, prefiguran y ayudan a moldear la pregunta de investigación.

En adelante, tomaremos el caso quimérico de la docente Dora Pinto Velandia, estrategia de ejemplificación elegida con el fin de simular el proceso de la búsqueda inductiva de datos que la llevará a la formulación de un proyecto investigativo en pedagogía de la lengua materna. Creeremos, entonces, que Dora es docente de la fabulada Institución Educativa Mis Primitivos Pasos, quien se desempeña como profesora de lengua castellana en un grupo de estudiantes, pertenecientes al ciclo $\mathrm{V}$, grado décimo. Ella observa que sus discípulos del salón 1008 (quién), fuera del aula defienden sus puntos de vista con versatilidad y cierta eficacia (qué 1, dónde 1 y cuándo 1) pero, dentro del aula (dónde 2 y cuándo 2) no pueden defender exitosamente sus ideas, especialmente las que comprometen cierto esquema de un saber disciplinar o interdisciplinar (qué 2) frente a la profesora (cómo), bien sea de forma oral o escrita (qué del cómo). Así las cosas, se les dificulta organizar una apuesta discursiva que sirva para la defensa de un punto de vista (para qué del cómo) y, la mayor de las veces, en el aula (cuándo y dónde 2) no encuentran con destreza razones que justifiquen su idea central, a lo que se suma que no concluyen y que la calidad de sus argumentos violan normas interactivas de cooperación como las de calidad y cantidad (por qué 1 ). Todo esto, evidentemente, hace que sus interacciones verbales (qué $2^{\prime}$ ) y sus textos escritos de tipología con dominancia argumentativa (qué $2^{\prime \prime}$ ) presenten baja textualidad, especialmente en la definición y desarrollo temático, y en la organización persuasiva de sus elementos (por qué del cómo a propósito del qué en el dónde). No obstante, lo que más le inquieta a Dora es el desempeño de la producción escrita de textos argumentativos; esto es, textos que intentan defender un punto de vista.

Asimismo, gracias a algunos escritos construidos en clase por parte de los educandos, Dora ha podido observar cómo se presentan deficiencias en la superestructura textual (dispositio textual) y en el uso de las ideas nucleares y satelitales (progresión gracias a vías hipotácticas o paratácticas) debido, en parte, por un uso inadecuado de la cohesión lógica o relacional (conectores de argumentos fuertes y débiles) y, también, por la falta de claridad comunicacional en el desarrollo de las ideas, visto a la luz gracias a las frecuentes galimatías y peroratas usadas (tipos, orden y calidad de las razones). Estas dificultades pueden ser explicadas, de hecho, como ausencia de conocimiento declarativo lingüístico-estructural y funcional (o discursivo) que poseen los educandos de la argumentación, si es entendida como práctica social cotidiana, tanto en la escuela como en la vida cotidiana, y su distinción de otras secuencias textuales propias de la escuela (Adam, 1992) y que configura tanto prácticas pedagógicas como concepciones cuya función comunicativa está siempre orientada a un a quién de la interacción (interlocutor) ${ }^{3}$.

Pero, también, Dora ha podido observar las clases de sus colegas de área, además de dialogar y recoger testimonios de los más cercanos. Esta acción le ha permitido constatar que ellos, incluyéndose, no parten de escenarios comunicativos reales a la hora de fijar ejercicios escriturales a sus educandos sino que, más bien, se sostiene una preocupación puramente formal y cosmética de los productos, acción que evidencia una concepción compartida de la escritura como producto y no como un proceso tanto comunicativo como sociocognitivo. Finalmente,

3 "[...] La argumentación como secuencia textual aparece en muchas de las actividades discursivas características de la vida social pública o privada [...]. En un sentido amplio, la argumentación es una práctica discursiva que responde a una función: la que se orienta hacia el receptor para lograr su adhesión" (Calsamiglia y Tusón, 2002, p. 294). 
Dora nota que sus colegas revisan y valoran los textos de secuencia argumentativa generados por sus estudiantes sin claridad ni sistematicidad de criterios evaluativos (uso de retículas de evaluación formativa), lo que los lleva a desconocer a través de qué ítems será valorado el producto entregado, y obligando a la mera valoración sumativa y certificativa.

Es así como el rol de observadora que ha venido agenciando Dora cede su paso al rol de etnógrafa, lo que la azuza a traducir las preguntas iniciales en una problemática la cual, gracias al levantamiento de datos inductivos (o material in situ), deberá tomar más cuerpo, cuerpo-del-delito si se quiere, pues, como sucede en el mundo judicial, aquí también hay que buscar evidencias de esa ausencia observada; esto es, elementos materiales, huellas, rastros o todo indicio (indicium: revelación, denuncia) que el etnógrafo pueda acumular para patentizar problemas relacionados con la escritura de textos argumentativos, en este caso. Ahora, para completar esta labor etnográfica, nuestra investigadora asimilará y madurará la información ordenándola y apostando un diálogo en tres campos de trabajo (tabla 2).

Ahora bien, para buscar, recopilar y asimilar este tipo de documentos, Dora logra el empoderamiento rápido y efectivo de las lecturas que debe realizar para triangular estos tres campos, siguiendo algunos tópicos generales que le sirven de guía lectora; así, por ejemplo, la definición del proceso dentro de la modalidad escrita de la lengua (proceso escritor), la función del proceso, las estrategias usadas para lograr avances en esa habilidad (según el ciclo), las dificultades previstas o localizadas en ese ciclo, las tipologías textuales previstas (entre ellas, la de predominancia argumentativa), y las formas de evaluación contempladas (García-Dussán, 2015).

Así las cosas, en esa búsqueda encuentra que, según los Referentes didácticos (Correa y Dimaté, 2010), lectura y escritura son entendidos como prácticas socioculturales, lo que significa que son formas de comunicación situadas y con auditorios explícitos; mientras que los Lineamientos curriculares (MEN, 2008), en relación con el proceso de escritura, plantean que no es solamente una codificación de significados a través del uso de reglas lingüísticas, sino que es un proceso social mediante el cual cada individuo usa necesariamente su contexto cognitivo y social para recrear realidades. Aún más, afirma que la escritura es

[...] un proceso que a la vez es social e individual en el que se configura un mundo y se ponen en juego saberes, competencias, intereses, y que a la vez está determinado por un contexto sociocultural

Tabla 2. Campos constitutivos de una lectura etnográfica del contexto desde el aula

\begin{tabular}{|c|c|c|}
\hline Campo político & Campo cartográfico & Campo etnográfico \\
\hline $\begin{array}{l}\text { Compilado de textos provenientes del } \\
\text { MEN }\end{array}$ & $\begin{array}{l}\text { Acopio de documentos que despliegan } \\
\text { información teórica }\end{array}$ & $\begin{array}{l}\text { Instrumentos que admiten recolección } \\
\text { sistémica del campo real }\end{array}$ \\
\hline $\begin{array}{l}\text { Lineamientos curriculares de lengua } \\
\text { castellana (1998). } \\
\text { Estándares básicos de lenguaje (2003). } \\
\text { Referentes para la didáctica del lenguaje } \\
\text { por ciclos (2010-2011). } \\
\text { Plan Sectorial de Educación 2010-2014, } \\
\text { del MEN. } \\
\text { Lineamientos curriculares para preesco- } \\
\text { lar en Colombia. } \\
\text { Resultados de pruebas nacionales e } \\
\text { internacionales sobre la modalidad oral } \\
\text { o escrita (PISA, Compensar...). }\end{array}$ & $\begin{array}{c}\text { Tesis de maestría. } \\
\text { Tesis de doctorado. } \\
\text { Artículos resultado de investigación. } \\
\text { Compilaciones de memorias de congre- } \\
\text { sos. } \\
\text { Libros de teóricos. } \\
\text { Libros, compilación de artículos teóricos } \\
\text { o reflexivos. }\end{array}$ & $\begin{array}{c}\text { Encuestas. } \\
\text { Entrevistas semiestructuradas. } \\
\text { Notas de campo (narración de un he- } \\
\text { cho, interrelación teórica, preguntas/hi- } \\
\text { pótesis, contextos sociales e históricos). } \\
\text { Pruebas y talleres. } \\
\text { Cuadernos o carpetas. } \\
\text { Reportes de caso y soportes } \\
\text { audiovisuales. }\end{array}$ \\
\hline
\end{tabular}

Fuente: elaboración propia. 
y pragmático que determina el acto de escribir: escribir es producir el mundo" (MEN, 2008, p. 27).

Como es de notar, estos documentos son fundamentales de consultar y tener presente, por cuanto son la base común a toda posible praxis docente en nuestra nación y, también, referentes básicos para valorar el devenir de esas prácticas, tal como ocurren en la realidad. Asimismo, para ampliar aún más estas definiciones, Dora busca autores que le aclaren implicaciones del enfoque sociocultural de la lectura y la escritura; iniciativa que le permite conectar inmediatamente el campo político con el cartográfico (o teórico cardinal). Entonces, tras la revisión de algunos artículos de investigación, tesis de maestría o doctorado, y memorias de eventos propios de maestrías especializadas en estas áreas temáticas de estudio, encuentra más elementos orientadores a propósito de la teoría y la metodología que ilumina su propio esfuerzo.

Ahora, para aprovechar mejor todo este esfuerzo de búsqueda de información, se vale de experiencias anteriores, producto de rastreos etnográficos avanzados previamente en la MPLM (antecedentes investigativos), y comienza a sistematizar sus actos lectores en matrices-resumen; todo esto porque sabe que se pueden repetir de forma similar en su respectivo espacio educativo local. Es decir, esos tópicos frecuentes consienten alinear y preparar la ubicación de la información y los datos de su lectura etnográfica particular, como por ejemplo, el enfoque, las concepciones docentes, los objetivos, las didácticas empleadas, los tipos de textos preferentemente usados, las estrategias didácticas reiterativas, la intencionalidad, los rituales y ambientes de aprendizaje, los tipos de conocimiento privilegiados, las formas de evaluación usadas, etc.

Adicionalmente, Dora ha dedicado algún tiempo para sistematizar unas nociones básicas sobre la argumentación, simplificadas gracias a la búsqueda de varios manuales de análisis discursivo (v. gr. Calsamiglia y Tusón, 2002), y las ha resumido en retículas operativas, puesto que ella misma debe comenzar a dominar el metalenguaje de su investigación para poder dar nombre a las ausencias más significativas de sus estudiantes en relación con la producción escrita de textos argumentativos. Para ello, se permite construir una guía que aglutina lo más elemental de la concepción semiolingüística de un texto con predominancia argumentativa que revele elementos de la inventio (o definición del tema del que se va a hablar), la dispositio (o superestructura); todo esto con la ayuda de supuestos teóricos revisados en espacios académicos que tratan sobre el eje lingüístico-discursivo que le ha ofrecido la MPLM en el primer año de su formación posgradual.

Igualmente, nuestra docente-investigadora ha determinado diferencias entre las perspectivas psicolingüística y sociocultural de la escritura, pues sabe que documentos como los Lineamientos y los Referentes se basan en estas para pensar el proceso escritor en nuestras escuelas. Esta es una decisión muy importante porque, desde ahora, ella comenzará a valerse de insumos necesarios para adjudicarse una posición teórica particular que le servirá para anclarse desde allí y avanzar en su investigación, bien sea postura psicolingüística, la sociosemiótica, la sociocultural o la imbricación posible entre algunas de ellas (cfr. García-Dussán, 2015).

Por otra parte, dado que las posturas sociocultural y psicolingüística-metacognitiva son muy visibles tanto en las apuestas de entendimiento de los documentos políticos, como de algunos autores consultados y algunos referenciados en la lectura de tesis y artículos de investigación consultados por Dora, decide construir fichas mnemotécnicas que le facilitarán el trabajo lector frente a su búsqueda inmediata; a saber: fijar un problema de investigación a partir del camino inductivo de investigación. Así, por ejemplo una ficha que revele el entendimiento de qué es escribir, qué es texto y cómo se concibe el aprendizaje de la escritura desde la perspectiva psicolingüística y sociocultural.

Sin duda, este tipo de información materializada y sistematizada le será útil, especialmente para preparar talleres diagnósticos sobre el estado real de los estudiantes y que, en este caso ejemplar, versa sobre la escritura de textos argumentativos. De esta manera, la docente-investigadora cubre las actividades 
propias del campo etnográfico, el cual involucra el conjunto de registros que deben construirse y aplicarse a los actores de la escuela para obtener información local sobre los tópicos trazados arriba y que, a la postre, permitirán comparar y asociar lo establecido entre el deber ser y lo que en realidad sucede en la IED Mis Primitivos Pasos, supuestos metódicos que constituyen la llamada lectura etnográfica del contexto (LEC).

Por ejemplo, con los estudiantes resulta ventajoso aplicar una secuencia de talleres-diagnósticos, cuyo objetivo puede ser el de determinar los elementos de la inventio y de la dispositio de un texto de secuencia argumentativa y tomar esa comprensión, manifestada en un punto de vista sobre el punto de vista del autor leído como partida para que el grupo de educandos redacte un texto de dominancia argumentativa, cuidándose de acompañar el ejercicio, eso sí, con una consigna suficientemente clara y completa para evitar confusiones en su desarrollo.

Ahora, como se deben evaluar los textos argumentativos, Dora reúne y acopia una retícula esencial que le permite obtener información precisa sobre fortalezas y debilidades de los escritos producidos por su grupo de estudiantes. El resultado puede ser el indicado en la tabla 3.

Este tipo de labores se puede complementar, generalmente, con acciones etnográficas como las que abrevia la tabla 4.

A esta altura de su proceso, Dora ya ha acumulado un corpus etnográfico, obtenido gracias a entrevistas a actores de la escuela (v. gr. profesores y estudiantes), además de una revisión crítica de cuadernos de estudiantes y algunas pruebas ejecutadas sobre escritura argumentativa. A esto se suma la pila de encuestas sobre preferencias y concepciones a estudiantes, integradas con fragmentos de algunas grabaciones de clase sobre su desempeño pedagógico. Entonces, llega el momento donde aparece una pregunta que apunta sobre lo que debe hacer con todo ese material recopilado. La respuesta es aparentemente simple: analizar los datos; esto es, buscar sentido(s) en relación con un objetivo, que aquí es el de delimitar teoréticamente para obtener una pregunta de investigación; esa 'estrellita de

Tabla 3. Rejilla de evaluación cualitativa sobre aspectos textuales de un texto con predominancia argumentativa

\begin{tabular}{|c|c|c|c|}
\hline & Elemento & Preguntas orientadoras & Cometarios \\
\hline \multirow{10}{*}{$\begin{array}{l}\stackrel{O}{E} \\
\underline{\mathbf{Z}} \\
\underline{\underline{Z}}\end{array}$} & Dispositio & ¿Se evidencia al menos, exordio, demostración y epílogo? & \\
\hline & $\begin{array}{l}\text { Elementos } \\
\text { pragmáticos }\end{array}$ & $\begin{array}{l}\text { ¿Es clara la intención de llevar al receptor a una posición a } \\
\text { favor o en contra de un punto de vista? }\end{array}$ & \\
\hline & & ¿Se explicita una(s) intención(es) determinada(s)? & \\
\hline & & $\begin{array}{l}\text { ¿La progresión de las razones son pertinentes con la inten- } \\
\text { ción? }\end{array}$ & \\
\hline & $\begin{array}{l}\text { Elementos } \\
\text { semánticos }\end{array}$ & $\begin{array}{l}\text { ¿Los diferentes tipos de argumentos usados apoyan el punto } \\
\text { de vista? }\end{array}$ & \\
\hline & & $\begin{array}{l}\text { ¿Los diferentes tipos de argumentos se apoyan coherentemen- } \\
\text { te entre sí? }\end{array}$ & \\
\hline & & ¿Se identifican los referentes con facilidad? & \\
\hline & $\begin{array}{l}\text { Elementos } \\
\text { sintácticos }\end{array}$ & ¿Es pertinente el uso de conectores para expresar relaciones? & \\
\hline & & ¿Los pronombres y artículos mantienen la referencia? & \\
\hline & & $\begin{array}{l}\text { ¿Los signos de puntuación relacionan adecuadamente la } \\
\text { secuencia oracional del texto? }\end{array}$ & \\
\hline
\end{tabular}

Fuente: elaboración propia. 
Tabla 4. Registros in situ que se pueden avanzar en una lectura etnográfica

\begin{tabular}{|c|c|c|}
\hline Tipo de registro & $\begin{array}{c}\text { Tópicos posibles que indaga con más } \\
\text { profundidad el registro }\end{array}$ & $\begin{array}{l}\text { Actor social } \\
\text { demandado }\end{array}$ \\
\hline $\begin{array}{l}\text { Encuestas a través de cuestionarios } \\
\text { prediseñados. }\end{array}$ & $\begin{array}{l}\text { Definición de la habilidad. } \\
\text { Función de la habilidad. } \\
\text { Estrategias usadas según el ciclo. } \\
\text { Dificultades previstas, según el ciclo. } \\
\text { Formas de evaluación. }\end{array}$ & $\begin{array}{l}\text { Docentes } \\
\text { Estudiantes } \\
\text { Directivos }\end{array}$ \\
\hline $\begin{array}{c}\text { Entrevistas } \\
\text { semiestructuradas. }\end{array}$ & $\begin{array}{l}\text { Definición de la habilidad. } \\
\text { Función de la habilidad. } \\
\text { Estrategias usadas según el ciclo. } \\
\text { Dificultades previstas, según el ciclo. } \\
\text { Formas de evaluación. }\end{array}$ & Docentes \\
\hline $\begin{array}{l}\text { Pruebas, trabajos extraclase } \\
\text { o talleres. }\end{array}$ & $\begin{array}{l}\text { Función de la habilidad. } \\
\text { Estrategias usadas, según el ciclo. } \\
\text { Dificultades previstas, según el ciclo }\end{array}$ & Estudiantes \\
\hline $\begin{array}{l}\text { Revisión de cuadernos del área de } \\
\text { lenguaje o afines o carpetas PILEO. }\end{array}$ & $\begin{array}{l}\text { Función de la habilidad. } \\
\text { Estrategias usadas, según el ciclo. } \\
\text { Dificultades previstas, según el ciclo }\end{array}$ & Estudiantes \\
\hline $\begin{array}{l}\text { Diarios o notas de campo } \\
\text { (cuadernos de campo o } \\
\text { libretas de bolsillo). }\end{array}$ & $\begin{array}{c}\text { Descripción de las interacciones dentro del aula, } \\
\text { con el fin de analizarlas para obtener generaliza- } \\
\text { ciones que puedan reforzar lo que se encuentre } \\
\text { en otros tipos de registros. }\end{array}$ & $\begin{array}{l}\text { Interacción } \\
\text { profesor/estudiantes. }\end{array}$ \\
\hline
\end{tabular}

Fuente: elaboración propia.

Belén' que, en adelante, tutelará el proceso investigativo de nuestra colega Pinto Velandia.

Gracias a las premisas ofrecidas por las apuestas metódicas de sistematización de datos inductivos, sabemos que analizar un corpus es obtener rasgos o propiedades comunes que actúan como categorías de trabajo (Martínez, 1996; Ruiz, 2006), todo esto logrado gracias a las habilidades que Dora ha fortalecido en prácticas descriptivo-analíticas sobre los niveles de lengua y análisis del discurso. Esto le obliga a nuestra docente a un análisis deductivo-global; esto es, arrastrando las categorías teóricas hacia los registros y un análisis de forma inductiva-local, donde se buscan categorías emergentes o empíricas ${ }^{4}$. Este tipo de análisis suele seguir unos pasos que se ejecutan para dar sentido a los datos obtenidos en la labor etnográfica, y se muestra en la tabla 5 .

4 “[...] Empezar a crear categorías es una manera de comenzar a leer y a pensar sobre los datos, de un modo organizado y sistemático" (Coffey y Atkinson, 2003, p. 38).
De esta suerte, Dora sabe que debe hacer una labor de supresión de información irrelevante (= seleccionar y fragmentar), seguida de una de una acción de generalización (= recontextualizar y organizar). Tras adelantar estas acciones, lo encontrado es traducido en categorías teóricas (= codificar), las cuales se fijan de manera sintética para mostrar los patrones que dan cuenta de la complejidad de lo revisado etnográficamente. El resultado de esto se puede reducir y presentar a la comunidad académica como se indica en la tabla 6 .

Adicionalmente, animada por la búsqueda y lectura de documentos de su IED, Dora encuentra que el Plan de Área de la IED Mis Primitivos Pasos revela como una meta para ciclo $\mathrm{V}$ el auxilio a los estudiantes en la producción de textos: ensayos, informes de laboratorio, reseñas, columnas de opinión y crónicas. Aún más, según el Plan, la producción escrita debe ser trabajada desde el aula como un proceso, articulando conceptos lingüísticos y comunicativos puestos en juego en el acto de escribir. No obstante, el documento no precisa 
qué tipo de dificultades se prevén en este ciclo con relación a la escritura de textos, y menos aquellos de dominancia argumentativa. Asimismo, al contrastar lo dicho en el Plan con el proyecto de participación que orienta el desarrollo de las competencias comunicativas o PILEO, se encuentra que la IED promete incentivar la necesidad y el gusto de escribir en sus alumnos. De hecho, el segundo objetivo específico afirma que se debe promover la creatividad y la rigurosidad en la elaboración de escritos de disímiles tipos; pero los resultados de su observación y su propia experiencia revela que este proyecto no se dinamiza frecuente ni sistemáticamente en la Institución, sino que, a lo sumo, hay actividades en algunas áreas del saber que solo propenden por la producción de una diversidad textual, limitada -por cierto-, pero teniendo en cuenta la ortografía y algunos aspectos de la cohesión gramatical (con descuido de la lógica y la lexical).

A pesar de todas estas contradicciones encontradas entre el decir y el hacer, Dora rescata del PEI que hay una sección donde se manifiesta que existen $y$, en alto grado, problemáticas suficientemente identificadas; entre ellas: la ausencia de hábitos lectores entre los educandos; la dificultad de concebir las cualidades específicas de textos informativos, argumentativos o expositivos, y la profunda dificultad de producir textos con cohesión y coherencias aceptables; algo inexistente en el Plan. Adicionalmente, el documento afirma que la principal dificultad que se presenta es la falta de integración y apropiación de las demás áreas frente a este proyecto, asumiéndolo como distintivo del área de Humanidades, cuando se sabe que la lectura, la escritura y la oralidad son habilidades comunicativas necesarias para desarrollarse en cualquier lógica disciplinar. Entonces, dado que esto no es fácil de re-estructurar, decide trabajar en su nicho particular, con 20 estudiantes del salón 1008 (10 mancebos y 10 señoritas), generando una delimitación de tipo práctico que contempla condiciones temporo-espaciales; es decir, un cronograma de acción /fechas tentativas/, y una localización geográfica para avanzar su investigación (IED Mis Primitivos Pasos, jornada tarde). No obstante, también debe delimitar la estructura temática, pues, como advierte Tamayo y Tamayo: "[...] el 80 \% de las investigaciones fracasan por carecer de delimitación

Tabla 5. La codificación o mecanismo de descubrimiento

\begin{tabular}{cl}
\hline Acción & \multicolumn{1}{c}{ Cualidad } \\
\hline $\begin{array}{c}\text { Seleccionar } \\
\text { y fragmentar el corpus }\end{array}$ & $\begin{array}{l}\text { Con ayuda de criterios de calidad y suficiencia, se eligen los productos etnográficos } \\
\text { más significativos (resultados de entrevistas, encuestas, trascripciones de registros de } \\
\text { audio, talleres, pruebas/ejercicios, cuadernos de educandos, notas de campo...). }\end{array}$ \\
$\begin{array}{c}\text { Recontextualizar } \\
\text { y organizar }\end{array}$ & $\begin{array}{l}\text { Se determinan los elementos recurrentes/repetitivos/frecuentes (patrones) frente a } \\
\text { ciertos tópicos y elementos. }\end{array}$ \\
& $\begin{array}{l}\text { Se catalogan a través del uso de diacríticos (colores, marcas, preguntas...). } \\
\text { Se genera un índice, como el de los libros. }\end{array}$ \\
Codificar & Se establecen categorías que den cuenta de las recurrencias o patrones (no se crean, \\
& se arrastran de la teoría: categorías teóricas, apriorísticas o conceptos objetivadores) \\
que pueden desplegarse en subcategorías. \\
Se escudriñan categorías emergentes o no previstas en el paquete de categorías teóri- \\
cas (Ilamadas categorías emergentes o conceptos sensibilizadores). \\
Se reconstruye de forma creativa y dialógica (con las tres dimensiones) la codifica- \\
ción, sin descuidar los sistemas socioculturales de su producción.
\end{tabular}

Fuente: Coffey y Atkinson (2003). 
Tabla 6. Resultado de ausencias a través de instrumentos etnográficos

\begin{tabular}{|c|c|c|c|}
\hline $\begin{array}{l}\text { Instrumento } \\
\text { in situ }\end{array}$ & Tópico & $\begin{array}{c}\text { Categoría(s) } \\
\text { teórica(s) o } \\
\text { emergente(s) }\end{array}$ & Subcategorías \\
\hline $\begin{array}{c}\text { Cuestionarios y } \\
\text { entrevistas a } \\
\text { profesores. }\end{array}$ & $\begin{array}{l}\text { Concepción docente } \\
\text { sobre la escritura. }\end{array}$ & $\begin{array}{l}\text { Acción mecánica y } \\
\text { memorística. }\end{array}$ & $\begin{array}{l}\text { Repetición de ejercicios prefigurados. } \\
\text { Falta de contexto. }\end{array}$ \\
\hline $\begin{array}{c}\text { Entrevistas } \\
\text { focales a } \\
\text { docentes y docu- } \\
\text { mentos del colegio }\end{array}$ & $\begin{array}{l}\text { Estrategias didácticas } \\
\text { más usadas. }\end{array}$ & $\begin{array}{l}\text { Dictado o copia } \\
\text { directa del tablero. }\end{array}$ & $\begin{array}{l}\text { Trazo de grafemas. } \\
\text { Ortografía. } \\
\text { Cohesión y coherencia. }\end{array}$ \\
\hline (PILEO y de área). & & & \\
\hline $\begin{array}{l}10 \text { muestras tomadas } \\
\text { al azar de los cua- } \\
\text { dernos de español } \\
\text { (5 chicas y } 5 \text { chicos). }\end{array}$ & $\begin{array}{l}\text { Dificultades } \\
\text { encontradas }\end{array}$ & $\begin{array}{l}\text { Dimensión pragmática } \\
\text { del texto. }\end{array}$ & $\begin{array}{l}\text { Confusión en el tipo o secuencia discursiva. } \\
\text { Ausencia de la situación comunicativa. } \\
\text { No hay uso de intertextualidad o polifonía. } \\
\text { No se escribe desde una intención predefinida. } \\
\text { Textos con deficiencias en su cohesión lógica y } \\
\text { coherencia local. }\end{array}$ \\
\hline $\begin{array}{c}\text { Entrevistas a } 10 \\
\text { estudiantes del } \\
1008 .\end{array}$ & $\begin{array}{l}\text { Concepciones } \\
\text { estudiantiles sobre } \\
\text { escritura de textos } \\
\text { argumentativos. }\end{array}$ & Pausas o pasos. & $\begin{array}{l}\text { Falta de conciencia de los pasos que se necesitan } \\
\text { para planear y textualizar. } \\
\text { Ausencia de conocimiento de la intención de un } \\
\text { texto argumentativo. }\end{array}$ \\
\hline $\begin{array}{l}\text { Dos ejercicios } \\
\text { escriturales en clase. }\end{array}$ & $\begin{array}{l}\text { Errores comunes en la } \\
\text { escritura de ensayos de } \\
\text { textos argumentativos. }\end{array}$ & $\begin{array}{l}\text { Superestructura } \\
\text { Cohesión. } \\
\text { Coherencia. } \\
\text { Modalización. } \\
\text { Intertextualidad. } \\
\text { Propósito. }\end{array}$ & $\begin{array}{c}\text { No hay conclusión o cierre pragmático del texto. } \\
\text { Errores en el uso de conectores de argumentación } \\
\text { fuerte y débil. } \\
\text { Coherencia local hipotáctica impertinente. } \\
\text { Uso exclusivo de modalidad conjetural. } \\
\text { Inexistencia de citas y de alusiones. } \\
\text { No hay marcas de convencimiento ni de persuasión. }\end{array}$ \\
\hline $\begin{array}{l}\text { Análisis de un video } \\
\text { efectuado en una de } \\
\text { sus clases del salón } \\
1008 .\end{array}$ & $\begin{array}{c}\text { Estrategias didácticas y } \\
\text { modalidades } \\
\text { pedagógicas. }\end{array}$ & Práctica docente. & $\begin{array}{c}\text { No hay actividades para indagar ideas previas sobre } \\
\text { el tema. } \\
\text { Propuesta de una organización en grupos, y trabajo } \\
\text { a partir de preguntas, pero sin puesta en común del } \\
\text { trabajo realizado. } \\
\text { Ausencia de actividades para volver sobre las ideas de } \\
\text { la clase con el fin de clarificar, intercambiar o expo- } \\
\text { ner a los alumnos a situaciones de conflicto cognitivo. }\end{array}$ \\
\hline
\end{tabular}

Fuente: elaboración propia.

del tema, es decir, por ambición de tema" (2011, p. 122).

Por tanto, nuestra investigadora debe seguir en esa exigencia de la delimitación, frente a lo cual debe relacionar los campos para encontrar el énfasis y huella personal de su investigación, previendo si es de intervención o de comprensión fenoménica. De esta suerte, en este momento de su labor ha avanzado una lectura etnográfica del contexto (LEC) exitosamente.
Tendrá tiempo de seguir enriqueciendo esta labor en términos teóricos, acompañada de su tutor; pero, mientras eso ocurre, es el momento de detenerse y de pasar del planteamiento a la delimitación final del problema. Veamos, por último cómo, adelantado el trabajo de revisión de documentos, y vista la reducción de las descripciones a nivel etnográfico (análisis y codificación), Dora puede ahora desplegar un diálogo entre los campos político, cartográfico y etnográfico; 
esto es, a concebir relaciones posibles en una fina red de asociaciones, y que podemos Ilamar, sin más, triangulación de datos y que pre-figuran el problema.

\section{DEL PLANTEAMIENTO DEL PROBLEMA A SU DELIMITACIÓN LÓGICAY SOCIAL}

Efectivamente, Ilega el momento en el que Dora toma los tres redondeles de la LEC para poder dar cuenta dónde está justamente la dificultad o ausencia más significativa que permitirá proyectar la investigación a través de la postulación de un problema concreto. Para ello, redacta todas las posibles aristas de unión como, por ejemplo:

1. Pese a que los documentos políticos resaltan la dimensión sociocultural de la escritura, ni en las concepciones docentes, ni en las prácticas de los docentes del área de lengua castellana aparecen elementos que lo confirmen. Lo que se evidencia, más bien, es que la escritura no es creación de aspectos de un estado-de-cosas, por lo que este tipo de procesos se toman más como meros productos que no ameritan revisión y que está en franca animadversión con la situacionalidad real de comunicación (Cassany, 1993) y, por tanto, con las intenciones de convencer o persuadir, tan fundamentales en la vida social y en el desempeño laboral (Camps, 1990).

Asimismo, según los Lineamientos curriculares, los estudiantes deben aproximarse a la escritura como pre-texto para dar cuenta de su relación con el mundo. En esto es fundamental la producción de diferentes tipos (o secuencias) de textos; pues tal como lo plantea el MEN, "[...] los diferentes usos sociales del lenguaje, lo mismo que los diferentes contextos, suponen la existencia de diferentes tipos de textos" (2008, p. 36), pero las encuestas a estudiantes y su confirmación con la revisión de cuadernos, corrobora la preferencia de textos narrativos, pese a estar en ciclos avanzados. Y, si bien los seres humanos conquistamos en el mundo social gracias a la narración, que permite conformar vivencias y modos de pensar y sentir (Brunner, 2003), también es cierto que todos debemos cultivar formas para defender puntos de vista y, así, ser más exitosos en la vida social. De ahí la necesidad de fortalecer las capacidades persuasivas de los educandos (Tusón, 1997).

2. Se da prioridad a la argumentación en los Referentes para la didáctica del lenguaje en el quinto ciclo (Correa y Dimaté, 2010), esto es, a "[...] la habilidad para organizar sus discursos y respaldarlos con argumentos que se originan en sus vivencias, en el reconocimiento de sus contextos, en los saberes científicos que han venido construyendo, etc." (p. 33). Sin embargo, lo que se evidencia es que las habilidades que presentan de los estudiantes tanto en sus pruebas, en el video de sus textos de dominancia argumentativa construidos para el Día del Idioma y, también, en los cuadernos, no les permiten defender sus puntos de vista eficientemente, lo que impide que el educando ejecute un hacer-creer o un hacer-hacer, o ambas cosas a un receptor determinado; de suerte que sus productos argumentativos no cumplen los cánones propios de esta secuencia, centrados en un aparato de razones que soportan un punto-de-vista (Cuenca, 1995, p. 23).

3. Por otra parte, los resultados de entrevistas a profesores y estudiantes dejaron ver que los maestros no conciben la escritura como un proceso comunicativo, ni mucho menos cognitivo, metacognitivo y metalingüístico. Además, reconocen que son repetitivos y poco creativos fundando talleres de escritura, lo cual está es 
disonancia con la teoría, pues "[...] para aprender a leer y escribir, los alumnos tienen que participar en actividades diversas de lectura y escritura con finalidades, interlocutores y ámbitos de interacción diversos para aprender la complejidad de los escritos" (Camps, 2003, p. 34). Asimismo, Dora no encontró evidencias sobre el reconocimiento del texto académico como artefacto condicionado por variables socioculturales, lo cual sucede a pesar de que el proyecto PILEO de la IED afirma que los docentes deben prestar atención al proceso escritor con la ganancia adicional, por parte del alumno, de poder concienciar sus dificultades en el proceso escritor y regular el acto como práctica o ritual social.

4. La revisión de los cuadernos de los jóvenes dejó ver, a su vez, que priman actividades de elaboración de mapas conceptuales como estrategia de producción para dar cuenta de las lecturas realizadas. No obstante, en este tipo de ejercicios no hay una pauta inicial sobre su elaboración, como tampoco se encuentran indicaciones sobre la planificación para obtener datos principales del texto escrito leído; todo esto hace que la producción escrita quede como la elaboración de estos recursos sin el uso de estrategias cognitivas y metacognitivas que favorezcan su desarrollo. En suma, se explicita trabajo con resúmenes a través de mapas conceptuales, pero no se establece con claridad la forma adecuada para elaborarlos ni para hacer de la escritura un proceso que demuestre niveles superiores a nivel ejecutivo, por lo que no hay huellas de una escritura instrumental, ni mucho menos epistémica (Wells, 1987). Esto va en claro detrimento con la planificación, la textualización y la revisión, es decir, con los subprocesos que actúan de forma dinámica y recurrente entre sí, y que permiten a un escritor determinar en qué punto se encuentra el desarrollo del texto, así como las dificultades por las cuales está atravesando (Flower y Hayes, 1996).

Es así como el ejemplo muestra que la investigadora tiene un arsenal de categorías evidenciadas con registros, que son la materia prima para demarcar su problema. Se tiene, entonces, que dentro del proceso escriturario de la modalidad escrita de la lengua (MEL), se trabajará con textos donde predominen secuencias argumentativas, haciendo cualificación de elementos concretos del nivel semántico-pragmático, que es donde se manifiesta falta de dominio por parte de los estudiantes (inventio y dispositio). La concepción preferida por Dora es la psicolingüística, metacognitiva, dado que permite fluctuar en fases y describe actividades propias; asimismo el énfasis se hará sobre la fase de la planeación y la planificación de este tipo de textos (qué, cómo, por qué y a quién), dado que aprovechará la intervención en el marco de la Feria de Ciencias de la IED nombrada, lo que asegura, también, que se hará un refuerzo en estrategias de cohesión lexical y relacional, en el nivel sintáctico.

De esta manera, Dora ya se atreve a formular su pregunta, base de la arquitectura investigativa así: “¿De qué manera fortalecer la composición de textos argumentativos a través de acciones de planificación y redacción múltiple en una población de estudiantes de ciclo $\mathrm{V}$ de un colegio distrital bogotano?". Esta pregunta será sometida a una revisión cuando logre planificar y redactar el proyecto investigativo que se constituye en un paso de reflexión y abre las puertas a una investigación-acción. Este proyecto suele seguir la silueta de la tabla 7.

\section{A MANERA DE CONCLUSIÓN}

Así las cosas, todo este arrojo que se ha progresado detallando los pasos que sigue una supuesta investigadora, Dora Pinto, permite no solo confirmar que se pueden destilar problemas auténticos que justifican una intervención pedagógica con unos beneficiarios visibles en contextos reales, sino que 
Tabla 7. Proyecto de investigación. Silueta textual de un proyecto investigativo

Elemento Cualidad
textual

Planteamiento del problema

Delimitación del problema

Pregunta de investigación

\section{Subpreguntas de investigación \\ Justificación del problema}

\section{Objetivos de la investigación}

\section{Referentes teóricos básicos de la investigación}

\section{Referentes metodológicos proyectados}

Presentación general del área temática de la investigación con apoyo de documentos generales, perspectivas teóricas y breves antecedentes investigativos reposadas en artículos, libros, memorias de coloquios, etc., desde la cual se aborda el asunto temático a trabajar en la investigación.

Presentación conceptual y temporo-espacial de los aspectos esenciales del problema, sumado a los resultados de triangulación/diálogo entre los campos teórico, político y etnográfico (LEC).

Manifestada en una relación entre dos categorías. Su redacción implica el uso de adverbios de modo interrogativo (cómo, de qué manera, de qué forma, etc.), seguida del verbo que indica la intención y el alcance investigativo (fortalecer, potenciar, iniciar, cualificar, etc.), luego aparecerá la relación categorial (de qué manera fortalecer $\mathrm{X}$ a través de $\mathrm{Y}$ ) y que culmina con la presentación del grupo beneficiario y su lugar de ubicación geográfica.

Desglose en posibles cuestiones implícitas en la pregunta de investigación; cada subpregunta representa una parte del problema a investigar y se relaciona con los objetivos específicos de la investigación.

Justificar implica resolver pertinentemente algunas cuestiones, a saber:

1. ¿Para qué sirve la investigación?

2. ¿Qué proyección social tiene (¿quiénes se beneficiarán con los resultados?).

3. ¿Qué implicaciones cobija frente a ciertos problemas prácticos?

4. ¿Se llena algún vacío de saber?

5. ¿Se pueden generalizar los resultados a principios más prácticos?

6. ¿Qué se espera conoce con los resultados?

7. ¿Ayudará a re-definir un concepto o teoría?

8. ¿Ayuda a crear un instrumento para recoger o analizar datos?

El objetivo general (OG) es el fin último de toda la investigación; esto es, muestra qué se pretende lograr con la investigación en el largo plazo. Su función es orientar todo el proceso investigativo y es la modalidad afirmativa absoluta de la pregunta investigativa.

Los objetivos específicos (OE) son los pasos operativos que me permiten satisfacer ese OG; por tanto, sus resultados se esperan obtener en el corto plazo.

Definición operacional de las categorías que conforman el problema. Estas deben estar situadas en una concepción o perspectiva teórica determinada, así:

\begin{tabular}{lll}
\hline \multicolumn{1}{c}{ MEL } & \multicolumn{1}{c}{ MOL } & \multicolumn{1}{c}{ MestL } \\
\hline Psicolingǘstica & Lingüístico-discursiva & Estructuralista \\
Sociosemiótica & & \\
Sociocultural & Literaria & Semiológica \\
& Didáctica & Culturalista \\
\hline
\end{tabular}

\begin{tabular}{ll}
\hline Paradigma & Hermenéutico. \\
Método & Cualitativo. \\
Diseño & $\begin{array}{l}\text { Investigación acción, sistematización, estudio de caso, análisis de } \\
\text { contenido, etnometodología, estudios literarios, etc. }\end{array}$ \\
Otros detalles & $\begin{array}{l}\text { Etapas del proceso, según el diseño, características de la población con el } \\
\text { cual se desarrollará el proceso. }\end{array}$ \\
\hline
\end{tabular}

Bibliografía

Presentación de los libros, artículos, tesis y páginas web consultadas, siguiendo las normas APA.

Fuente: elaboración propia. 
ayuda también a depurar el camino (método) que se debe seguir cuando se desea iniciar una investigación siguiendo la vía inductiva, lo cual involucra un trabajo en tres campos de acción-reflexión y sus posibles puntos de contacto, y que ameritan, como se destacó arriba, una labor que trenza datos in situ, con datos teóricos y datos apiñados en investigaciones previas, siempre y cuando se realice eficientemente el tránsito de un tema a un problema, lo cual amerita también el translación de un sujeto observador a uno investigador, pasando por el rol de etnógrafo.

Pero, quizá, lo más significativo en ese esfuerzo es que, gracias al hipotético caso desarrollado se coteja, de manera concreta y ejemplar, cómo los docentes que trabajan en las áreas de Lengua Materna, ya in-vestidos con la bata de investigador, pueden cualificar su rol; esto es, cómo, desde el inicio de una labor de pesquisa, establecen acciones más sistemáticas y reflexivas y, con esto, generan desde el trabajo del planteamiento de sus investigaciones, los soportes para la producción de saber pedagógico. Ahora bien, en beneficio de este propósito, una forma regia de formación en investigación indica afinar el ojo y husmear con mayor acierto, lo cual es posible si se adecúa el inicio investigativo con una lectura-etnográfica. Finalmente, investigar (de investigare, vestigium) significa, "ir en busca de huellas e indicios". Y de aquí hay solo un paso para que esta tarea se asocie con un interés trans-formador, haciendo realidad aquella premisa que afirma que es posible que alguien (el docente-investigador) ayude a que la gente (la comunidad de educandos) se ayude a sí misma, promesa que genera utilidad y justicia a todas las investigaciones realizadas y por germinar en este campo interdisciplinar de las ciencias sociales.

\section{RECONOCIMIENTOS}

Gratitudes al Centro de Investigaciones y DesarroIlo Científico (CIDC), de la Universidad Distrital Francisco José de Caldas, pues gracias a su apoyo y financiación este artículo de reflexión es producto colateral de la investigación institucionalidad con el código 2454352415, en enero de 2016.

\section{REFERENCIAS BIBLIOGRÁFICAS}

Adam, J.M. (1992). Les textes: types et prototypes. Récit, description, argumentation, explication et dialogue. París: Nathan.

Baquero, P. (2006). La investigación en el aula en la universidad. Aportes para una revisión crítica. En: P. Baquero et al. Prácticas pedagógicas universitarias (pp. 53-95). Bogotá: ULS, p. 53-95.

Brunner, J. (2003). La fábrica de historias. Buenos Aires: Fondo de Cultura Económica.

Calsamiglia, H. y Tusón, A. (2002). Las cosas del decir. Barcelona: Ariel.

Camps, A. (1990). Modelos del proceso de redacción: algunas implicaciones para la enseñanza. Revista Infancia y Aprendizaje, 49, 3-19.

Camps, A. (2003). Secuencias didácticas para aprender a escribir. Barcelona: Graó.

Cassany, D. (1993). Reparar la escritura. Didáctica de la corrección de lo escrito. Barcelona: Graó.

Coffey, A. y Atkinson, P. (2003). Encontrar sentido a los datos. Estrategias complementarias de investigación. Medellín: Universidad de Antioquia.

Correa, J.L. y Dimaté, C. (2010). Herramienta para la vida: hablar, leer y escribir para comprender el mundo. Referentes para la didáctica del lenguaje del quinto ciclo. Bogotá: Secretaría de Educación del Distrito.

Cuenca, M. (1995). Mecanismos lingüísticos y discursivos de las argumentación. Comunicación, Lenguaje y Educación, 25, 34-67.

Flower, L. y Hayes, J. (1996). La teoría de la redacción como proceso cognitivo. Buenos Aires: Lectura y Vida.

García-Dussán, E. (2015). Investigación en lengua materna. Camino y Fundamentos. Bogotá: Editorial UD.

Geertz, C. (1998). La interpretación de las culturas. Barcelona: Gedisa.

Lakoff, G. y Johnson, M. (2004). Metáforas de la vida cotidiana. Madrid: Editorial Cátedra. 
Martínez, M. (1996). Categorización y análisis de contenidos En: La investigación cualitativa etnográfica (pp. 73-86). Bogotá: CLA.

Ministerio de Educación Nacional (MEN) (2008). Lineamientos curriculares de lengua castellana. Bogotá: Magisterio.

Parra, R.; Parra, F. y Lozano, M. (2006). Tres talleres: hacia una pedagogía de la investigación etnográfica en la escuela. Bogotá: Unidad Editorial Convenio Andrés Bello.

Ruiz, A. (2006). El análisis de contenido en la investigación en educación. En: A. Torres y A. Jiménez. La práctica investigativa en ciencias sociales (pp. 4558). Bogotá: UPN.

Tamayo y Tamayo, M. (2004). El proceso de la investigación científica. México: Limusa.

Tusón, J. (1997). La escritura. Una introducción a la cultura alfabética. Barcelona: Octaedro.

Velasco, H (1999). La lógica de la investigación etnográfica. Madrid: Trotta.

Wells, G. (1987). Aprendices en el dominio de la lengua escrita. En: Psicología y Educación. Realizaciones y tendencias en la investigación y en la práctica. Actas de las II Jornadas Internacionales de Psicología y Educación (pp. 57-72). Madrid: Visor-Aprendizaje / MEC.

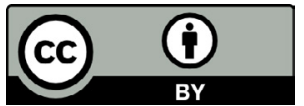

